\title{
Políticas de pertenencia y relaciones coloniales: la inmigración peruana en España*
}

\author{
María Asunción Merino Hernando \\ Universidad de Yale
}

\begin{abstract}
El presente artículo trata de contribuir al análisis del fenómeno de la inmigración en España con un enfoque histórico y global, tratando de superar el marco espacio temporal de este tipo de estudios, limitados al presente y a la unidad política del estado-nación. En el caso de las hermandades del Señor de los Milagros constituidas por los peruanos en Madrid durante la década de los noventa, se plantean nuevas perspectivas para la comprensión del proceso de reconstrucción de identidad de los inmigrantes, centrándose en la experiencia de éstos como sujetos postcoloniales que retornan a la metrópoli, ubicados en el centro de múltiples sistemas de referencia posibilitados por un mundo global e insertos en categorías de identidad impuestas por la sociedad receptora.
\end{abstract}

PALABRAS ClAVE: Unión Europea, España, inmigración, política migratoria, identidad, religión, asociacionismo inmigrante, postcolonial, globalización.

This paper tries to contribute to the analysis of the immigration in Spain with a historical and global approach, with the aim to overcome the common spatial and temporal analytical frames used in this type of studies, limited to the present and the political unit of the nation-state. I try to open new perspectives to understand the process of identity formation among immigrants collectivities, with the case of the brotherhoods of el Señor de los Milagros in Madrid, founded by Peruvian immigrants in Madrid. I focus on the Peruvian immigrants' experience, as postcolonial subjects coming back to the old metropolis, placed themselves both in the center of multiple systems of reference -facilitated by a global world - and in identity categories imposed by receiving society.

KEYWORDS: European Union, Spain, immigration, migratory politics, identity, religion, immigrant associations, postcolonial, globalization.

Desde mediados de la década de los ochenta, dada la doble conversión de España en país de inmigración y en miembro de la Unión Europea en 1985, un análisis de la bibliografía española sobre inmigración nos permite observar, entre otros elementos, su novedad y su herencia de los enfoques que abordaban la inmigración a países con mayor tradición migratoria en Europa. ${ }^{1}$

* Quisiera agradecer la ayuda prestada para la elaboración de este artículo a las siguientes personas: Elda González, Científico Titular en el Departamento de Historia de América del CSIC, Guillaume Boccara, Profesor visitante en el Departamento de Antropología de la Universidad de Yale y Eugenia Ramírez, Profesora Asociada en el Departamento de Antropología Social de la UNED.

1 Basta revisar las referencias bibliográficas de las obras más relevantes sobre inmigración en España. Ver como ejemplo los trabajos siguientes: Colectivo Ioé: "Los inmigrantes en España", Documentación Social, 66, Cáritas, Madrid, 1987; Giménez, Carlos (Coord.): Trabajadores Extranjeros en Madrid, Comunidad Autónoma de Madrid, Madrid, 1993. 
Uno de esos temas es el asociacionismo inmigrante; ${ }^{2}$ tanto en los estudios sobre el caso español como sobre el europeo, se analiza el papel de las asociaciones en las comunidades inmigrantes o en la interacción entre éstas y la sociedad receptora (facilitar la adaptación al cambio, resolver problemas, necesidades, etc.) centrándose, sobre todo, en las de carácter político. Sin embargo, estos análisis utilizan como unidad de análisis el estado nación — salvo el trabajo de Soysal ${ }^{3}$ y como marco temporal, el presente, ignorando el marco histórico — postcolonial en muchos casos- y global en el que suceden los actuales fenómenos migratorios.

En los noventa, somos testigos de la transformación del sistema capitalista, del desarrollo de las tecnologías de la información y, fruto de ello, del incremento de los flujos migratorios desde los países menos desarrollados a los desarrollados así como de las transformaciones en sus formas de llegada y asentamiento. ${ }^{4}$ Asistimos a una mayor concentración urbana de inmigrantes en países desarrollados, producto de las nuevas necesidades del capitalismo global, a la aparición de nuevas formas de pertenencia por parte de esas poblaciones, a nuevas formas de mapeo de la población por parte del estado ${ }^{5}$ y al surgimiento de modelos políticos distintos al estado-nación. ${ }^{6}$

El conjunto de estos nuevos fenómenos relacionados llevan, en el ámbito académico, a revisar nuestras herramientas analíticas y ampliar fronteras intelectuales en el estudio de los fenómenos migratorios: cuestionar el uso del estado-nación como unidad de análisis, ${ }^{7}$ abandonar la visión

2 Para el caso europeo: Rex, John et. al: Immigrant Associations in Europe, Gower, Brookfield, 1987; Layton-Henry, Zig: "Immigrant Associations", en Layton-Henry, Zig (Ed.): The Political Rights of Migrant Workers in Western Europe, Sage Publications, London, 1990, págs. 94-112; Castles, Stephen y Miller, Mark: The Age of Migration, MacMillan, London, 1994; Soysal, Yasemin: The Limits of Citizenship: Migrants and Postnational membership in Europe, Chicago University Press, Chicago, 1994. Para el caso español; Colectivo Ioé: "Los inmigrantes...”; Giménez: Trabajadores Extranjeros....

3 Soysal: The Limits of Citizenship...

4 Appadurai, Arjun: Modernity at Large, Cultural Dimensions of Globalization, University of Minnesota Press, Minneapolis, 1996; Castells, Manuel: The Rise of Network Society. Vol. 1. The Information of Age: Economy, Culture and Society, Blackwell Publishers, Oxford, 1996; Hannerz, Ulf: Transnational Connections, Routledge, London, 1996; Sassen, Saskia: Losing control? Sovereignty in an age of Globalization, Columbia University Press, Nueva York, 1995.

5 Wallerstein, Immanuel: "The Construction of Peoplehood: Racism, Nationalism and Ethnicity", en Balibar, Etienne y Wallerstein, Immanuel: Race, Nation and Class: Ambiguous Identities, Verso, Nueva York, 1991, págs. 71-85.

6 Sassen: Losing control?...

7 Soysal: The Limits of Citizenship... ; Castells: The Information of Age... 
sedentaria tradicional en la relación entre identidad y lugar, ${ }^{8}$ considerar nuevas formas de interacción entre comunidad y territorio, ${ }^{9}$ analizar las formas creativas de pertenencia y ciudadanía, ${ }^{10}$ rescatar el trabajo imaginativo de las comunidades en su producción de "localidad" pero, sobre todo, recordar una vez más que "la relación entre lugar, gente y cultura es una recreación histórica que ha de ser explicada, no un hecho natural dado". ${ }^{2}$

Tal vez, las sociedades, a pesar de los esfuerzos de homogeneización del estado-nación, nunca consideraran las relaciones entre su identidad y el lugar donde viven, su "localidad", un hecho natural dado ${ }^{13}$ ya que siempre estuvieron implicadas en un constante proceso de recreación de su identidad, en su interacción con otras sociedades; con seguridad que éste es el caso de los inmigrantes.

Por todo ello, este artículo pretende ubicar el análisis del asociacionismo inmigrante dentro del proceso de formación de identidades en poblaciones desplazadas, desde una perspectiva global e histórica, en un intento por superar el presente y la visión nacional como limitaciones analíticas espacio-temporales. El énfasis en las dimensiones histórica y global de la inmigración se origina en el interés por descubrir el potencial implícito de las asociaciones de inmigrantes a la hora de crear nuevas formas de pertenencia y negociar las categorías de identidad o las formas culturales impuestas por la sociedad receptora. La inmigración de los peruanos a España en la década de los noventa, poco después de que España se hubiera convertido en un país de inmigración y, al mismo tiempo, en un nuevo miembro de la Unión Europea, permitirá ahondar en la problemática aquí plantada.

Dentro de la inmigración peruana a España, analizo en particular, la sociabilidad peruana generada en torno a las hermandades peruanas devotas del Señor de los Milagros en Madrid. Estas asociaciones religiosas y la imagen a la que consagran su devoción, por regla tradicional, han de crear-

8 Malkki, Liisa: "National Geographic: The Rooting of Peoples and the Territorialization of National Identity among Scholars and Refugees" en Gupta, Akhil y Ferguson, James (Eds.): Culture, Power, Place: Explorations in Critical Anthropology, Duke University Press, Durham, 1997. nas 302-338.

9 Clifford, James: "Diasporas", Cultural Anthropology, 9 (3), Washington, 1994, pági-

10 Ong, Aihwa: Flexible citizenship: The Cultural Logics of Transnationality, Duke University Press, Durham, 1999.

11 Appadurai: Modernity at Large...

12 Gupta, Akhil: "Culture, Power and Place: Ethnography at the End of an Era." en Gupta y Ferguson (Eds.): Culture, Power, Place... pág. 4.

13 Appadurai: Modernity at Large... pág. 180. 
se en una parroquia y bajo su control ${ }^{14}$ en este caso, las autoridades parroquiales son españolas mientras los hermanos devotos son peruanos, lo que permite analizar un momento del encuentro cultural que se produce entre peruanos y españoles. Otro elemento que justifica el interés por este tipo de asociaciones es que la hermandad, instrumento de control y dominación en manos de los españoles durante la conquista del Nuevo Mundo, parece regresar a la metrópoli, pero en otro contexto y con otro significado.

El interés por estas asociaciones religiosas peruanas se incrementa por la presencia del elemento religioso. Éste, no sólo fomenta la cohesión social o la solidaridad del grupo ${ }^{15}$ sino que además se convierte en la piedra angular para la construcción de nuevas formas de pertenencia y, al mismo tiempo, en elemento de mediación y legitimación cultural, como ya lo fuera en los tiempos de la colonia española. ${ }^{16}$

La preocupación última de este trabajo es la de cuestionar esa percepción de los inmigrantes como creadores de un problema de diversidad cultural y, por tanto, contrarios a la asimilación. Cada vez es más común en países como Francia o España ver noticias en la prensa que justifican las manifestaciones racistas ante conflictos culturales entre comunidades inmigrantes y sociedad receptora. ${ }^{17}$ Como la antropóloga norteamericana Glick Schiller sugiere ${ }^{18}$ la tarea investigadora debe ir más allá de la deconstrucción de las políticas multiculturales para mostrar las relaciones de dominación que refuerzan la problematización de la diversidad cultural.

En este artículo se expondrá en primer lugar, el discurso político y social que cristaliza en España hacia los inmigrantes y que los peruanos encuentran a su llegada al país, una imagen que se construye y complementa en el espacio de la Unión Europea. A continuación mostraré la historia secular de las hermandades en Perú y, sobre todo, de la devoción al Señor de los Milagros. En el siguiente apartado analizaré la sociabilidad que las hermandades del Señor de los Milagros activan dentro la comunidad inmigrante peruana en Madrid y la forma de pertenencia que estas aso-

14 Rumeu de Armas, Antonio: Historia de la previsión social en España: cofradías, gremios, hermandades y montepíos, Revista de Derecho Privado, Madrid, 1944.

15 Durkheim, Emile: Las formas elementales de la vida religiosa, Akal, Madrid, 1982, pág. 39.

16 Adorno, Rolena: "The indigenous ethnographer: The "indio ladino" as historian and cultural mediation" en Schwartz, Stuart (Ed.): Implicit Understandings, Cambridge University Press, Cambridge, 1994, págs. 378-402.

17 Puigverd, Antoni: "De lo angelical a lo siniestro", El País, Madrid, 2 de junio de 2002.

18 Glick Schiller, Nina: "Introduction: Culture, Violence and Explanation", Identities 8 (1), Yverdon, Suiza, 2001, págs. 1-6. 
ciaciones articulan, mostrando el juego de poder y negociación que se genera en torno a las expresiones culturales de los peruanos.

\section{El discurso de la inmigración en España: el "inmigrante económico"}

Cuando el número de inmigrantes apenas era perceptible en España, ${ }^{19}$ en 1985, se promulgó la primera ley de inmigración en este país, coincidiendo con su recién estrenada pertenencia a la Unión Europea y la necesidad de cumplir con su papel adjudicado en ese espacio de guardián de la fortaleza comunitaria ante la inmigración no europea. ${ }^{20}$

Antes de que España ingresará la Unión Europea ya había heredado las prioridades establecidas por los estados miembros con mayor tradición migratoria sobre el tema de la inmigración no comunitaria. Tras la crisis económica de la década de los setenta, la inmigración había comenzado a ser percibida como un problema en países como Francia, Alemania y Gran Bretaña porque, entre otros motivos, el ritmo de crecimiento económico se había frenado y el mercado no podía absorber a una mano de obra extranjera que hasta entonces había sido llamada y que ahora era animada a retornar a sus países de origen. Se inició el cierre de fronteras, ante lo cual, los inmigrantes comenzaron a asentarse y traer a sus familias, lo que provocó la concentración de poblaciones portadoras de culturas diferentes a las europeas $^{21}$ y a la creación de una nueva categoría de inmigrante -el ilegal- $: 22$ un nuevo sujeto cuya presencia sería vinculada con la criminalidad y vista como una competencia desleal para el trabajador nativo a la hora de

19 En 1981 la presencia inmigrante sumaba el 0.5\% de la población total y diez años después apenas alcanzaba el 1\%. Cálculo extraído de fuentes oficiales. Ministerio de Asuntos Sociales: Anuario de Migraciones 1998, Dirección General de Ordenación de las Migraciones, Madrid, 1999, pág. 237.

20 Arango, Joaquín: "Becoming a country at the end of the Twentieth Century: The Case of Spain" en Russell, King et al. (Ed.): Eldorado or Fortress? Migration in the Southern Europe, St. Martin Press, Nueva York, 2000; Freeman, Gary, "Modes of Immigration Politics in Liberal Democratic States", International Migration Review 19 (4), Nueva York, 1992, págs. 881-902; Merino, Asunción: Historia de los inmigrantes peruanos en España, Biblioteca de Historia de América/CSIC, Madrid, 2002.

21 Kubat, Daniel: "France: Balancing Demographic and Cultural Nationalism" en Kubat, Daniel (Ed.): The Politics of Migration Policies, Center of Migration Studies, Nueva York, 1993, págs. 165-187; Coleman, David: "Immigration Policy in Great Britain", en Heckmann, Friedrich y Bosswick, Wolfgang (Eds.): Migration Policies. A Comparative Perspective, Enke, Sttugart, 1995, págs. 113-136; Layton-Henry, Zig: "British Immigration Policy and Politics" en Le May, Michael (Ed.): The Gatekeepers, Praeger, Nueva York, 1989, págs. 63-79.

22 Castles y Miller: The Age of Migration... pág. 78. 
negociar las condiciones laborales. ${ }^{23} \mathrm{Al}$ mismo tiempo, la crisis económica comenzó a mostrar sus secuelas en el incremento de la discriminación hacia los inmigrantes y la aparición de problemas económicos, sociales en sus comunidades (desempleo, baja escolarización, hacinamiento residencial, niveles de vida por debajo de la media nacional) ante los cuales los gobiernos habían ofrecido soluciones temporales en lugar de prevenir mayores complicaciones. ${ }^{24}$

Con la caída gradual de las fronteras intracomunitarias, acordada en el Tratado de Schengen de 1985 y la consecuente necesidad de seguridad dentro de ese territorio supranacional, el tema de la inmigración no europea se convirtió en un problema prioritario ${ }^{25}$ que iba a ser resuelto por los estados de la Unión de la misma manera que en los países de mayor tradición migratoria: máximo control y restricción ante la entrada de nuevos inmigrantes (imposiciones de visado y limitaciones de los permisos para reagrupación familiar y para refugiados), condicionada a las necesidades de la economía y a la protección de la mano de obra nativa y tratando de evitar la presencia de inmigrantes cuya cultura fuera demasiado diferente a la europea El problema migratorio iba a ser resuelto a través del cierre (obligatorio) de fronteras y de programas (recomendados) de integración para los inmigrantes, dentro de un discurso que vinculaba su presencia con la crisis económica y el racismo. ${ }^{26}$

Cuando España entra a formar parte de esta unidad supranacional, junto a la nueva ley de inmigración, asume el mismo discurso y las mismas categorías para los inmigrantes no europeos. ${ }^{27}$ El gobierno impone una política de férreo cierre de fronteras y comienza a propagar un discurso justificador de la legislación, en el que los extranjeros no europeos presentes en el territorio nacional (en especial los procedentes de América Latina

23 Miles, Robert y Thränhardt, Dietrich: "European integration, migration and processes of inclusion and exclusion" en Miles, Robert y Thränhardt, Dietrich: Migration and European Integration, Pinter Publishers Ltd, London, 1995, págs. 1-12.

24 Freeman: "Modes of Immigration Politics... págs. 892.

25 Den Boer, Monica: "Moving between bogus and bone fide, the policy of inlusion in Europe", en Miles y Thränhardt: Migration and European Integration... págs. 92-111; Lucas, Javier De: "Un país en tránsito. España ante las exigencias de la Unión Europea y la transformación de la inmigración. Incoherencias e incapacidad de respuesta", Seminario: Los desafíos políticos de la inmigración, Fundación Ortega y Gasset, Madrid, 9/10 de mayo de 1996 (inédito); Castles y Miller: The Age of Migration... pág. 78.

26 Miles, Robert: "Migration, Racism and the Politics of "Integration" in Europe". Ponencia presentada en la Conferencia L'integration locale des imigrées en Europe, París, 8 y 9 de octubre de 1990 (inédito).

27 Arango: "Becoming a country... ; Merino: La historia de los inmigrantes... 
y África, los más próximos cultural y geográficamente) serán clasificados en tres categorías: "inmigrante ilegal", "inmigrante económico" y "refugiado" sobre los que recaerá la exigencia de un visado para entrar y de un permiso para trabajar y residir en el país.

Antes de la incorporación de España a la Unión Europea, los extranjeros en este país, al margen de su procedencia, eran simplemente extranjeros, no se les consideraba inmigrantes económicos y mucho menos ilegales; la opinión pública y la producción bibliográfica estaban más preocupadas con los españoles emigrantes que con los extranjeros inmigrantes. ${ }^{28}$ Sin embargo, tras convertirse en miembro comunitario y en país de inmigración, el estado español genera nuevas clasificaciones para la población extranjera residente en su territorio: la divide en comunitarios y no comunitarios y, a estos últimos, en las categorías ya mencionadas.

La progresiva imposición de visados (de concesión muy restringida) a los diferentes colectivos de inmigrantes, mientras éstos siguen llegando a España debido a una coyuntura global, económica y política, lleva a los recién llegados que no lo traigan a entrar en la categoría de ilegales, sobre la que recae, como en el caso comunitario ya comentado, una serie de valoraciones negativas y dificulta la negociación de las condiciones de trabajo. ${ }^{29}$ Justo un año después de la llegada masiva de peruanos, en 1992, se impone a este colectivo la exigencia de visado para entrar en España. El visado de trabajo sólo se consigue con la presentación en la embajada española en Perú de un documento donde se afirme la futura contratación de ese inmigrante por un empleador español, lo cual, en principio y desde Perú, no resulta nada fácil de conseguir..$^{30}$

Con visado o sin él, los inmigrantes peruanos necesitan obtener además un permiso para residir y/o trabajar en el país; el permiso de trabajo, en la mayoría de los casos, se concede sólo en los sectores que la economía demande, esto es, en los empleos peor remunerados y menos reconocidos de la rama de construcción, servicio doméstico, limpieza, mensajería, restauración, etc. Durante los primeros años, los permisos van a ser temporales y la obtención de uno nuevo estará vinculada a la obtención de un contrato de trabajo, por lo que la ilegalidad para los peruanos es más una

28 González, Elda y Merino, Asunción: “Algunas aproximaciones al tema inmigratorio: notas sobre la producción bibliográfica española”, Revista de Ciencias Humanas 25, Florianópolis, 1999, págs.21-40.

29 Merino: La historia de los inmigrantes...

30 Ibídem 
probabilidad que una posibilidad y eso, además, les vuelve vulnerables a la detención, como más de uno ha experimentado. ${ }^{31}$

$\mathrm{Si}$, por un lado, la inmigración renacionaliza la política con la reafirmación de la soberanía nacional y el legítimo y estricto control de sus fronteras, por el otro, el capitalismo global desnacionaliza las economías nacionale ${ }^{32}$ en su necesidad de competitividad, contratando mano de obra barata y muy flexible, disponible en los países menos desarrollados. Pero la cuestión se vuelve aún más compleja en la esfera política y social si consideramos que el inmigrante no comunitario, además de verse convertido en sujeto de castigo también lo será en sujeto de Derechos Humanos, algo que sucede en el nivel comunitario ${ }^{33}$ y también en el caso español, con la aparición de un gran debate público durante la segunda mitad de los ochenta, en el que las organizaciones no gubernamentales (ONGs), incluidas las católicas y los sindicatos, entre otras, van a reivindicar los derechos de estos inmigrantes no europeos. En el espacio de negociación y debate que crean con las agencias estatales se acuerda la necesidad de controlar la entrada de los inmigrantes pero se redefine el significado del "inmigrante económico": ${ }^{34}$ un individuo frecuentemente indocumentado, que trabaja en la economía informal, con un nivel de vida inferior a la media española, que ha dejado su país empujado por la necesidad y con la expectativa de mejorar su condición social y que forma parte de la población marginal. ${ }^{35}$

Como vemos, fruto de esta consensuada política de identidad hacia el "inmigrante económico", los inmigrantes no comunitarios como son los peruanos, van a ser percibidos por la sociedad española como personas que tienen que entrar, que en muchos casos lo hacen de manera ilegal (de ahí, su relación con la criminalidad), de escasos recursos económicos, que trabajan en los empleos más devaluados socialmente y cuya presencia hay que limitar. Esta imagen devaluada, ${ }^{36}$ que justifica el que los peruanos ocupen una posición inferior en su nuevo destino, es la que recaerá sobre el colectivo peruano y caracterizará su encuentro con los españoles cuando éste se produce, a principios de la década de los noventa.

31 Ibídem.

32 Sassen: Losing control?... pág. 63.

33 Ibídem

34 Merino: La historia de los inmigrantes...

35 Colectivo Ioé: "Los inmigrantes... pág. 99-100 y 340.

36 Goffman, Erving: Estigma, la identidad deteriorada, Amorrortu, Buenos Aires, 1995. 


\section{Asociacionismo religioso y pasado colonial}

Desde sus orígenes medievales, las hermandades son asociaciones que surgen en torno a la devoción a un santo con una finalidad religiosa y una social: la preparación de los actos de culto y de la procesión un día señalado en el calendario litúrgico y la ayuda mutua entre los devotos. Se han de someter al control parroquial y seguir un conjunto de reglas que establecen las obligaciones económicas y religiosas de sus miembros y que un grupo directivo se encarga de hacer cumplir. Los hermanos contribuyen con una cuota o con donaciones y participan en cuestiones deliberativas como los presupuestos o la elección de los cargos principales. ${ }^{37}$

Tras el descubrimiento del Nuevo Mundo, esta forma de asociacionismo religioso fue impuesta por la Iglesia Católica sobre la población nativa con el objetivo de erradicar las creencias paganas en esas gentes y convertirlas al Cristianismo, mantenerlas bajo el control económico, político y cultural de la Corona española, ${ }^{38}$ obtener recursos para los gastos de culto como construcción y mantenimiento de las iglesias, al tiempo que fomentar la división étnica en la sociedad colonial (españoles, negros e indios) ${ }^{39}$ para evitar revueltas en las colonias. ${ }^{40}$

Sin embargo, entidades religiosas como éstas también fueron dotadas de otros significados por parte de la población nativa: les sirvió para mantener la propiedad de sus bienes comunales u organizar su explotación colectiva, resultó una forma de solidaridad y un espacio híbrido de adaptación a los cambios impuestos por la dominación colonial y, al mismo tiempo, de mantenimiento de algunas expresiones culturales propias. ${ }^{41}$

Estas asociaciones religiosas proliferaron en la Lima colonial, en torno a diferentes santos, y será en ese contexto en el que surja la devoción al

37 Rumeu de Armas: Historia de la previsión...; Bleiberg, Germán (director): Diccionario de Historia de España, Tomo I, Revista de Occidente, Madrid, 1968, págs. 862-863; López Muñoz, Miguel Luis: La labor benéfico social de las cofradías en la Granada Moderna, Universidad de Granada, Granada, 1994.

38 Celestino, Olinda y Meyers, Albert: Las Cofradías en el Perú: región central, Vervuert, Frankfurt, 1981.

39 Meyers, Albert: "Religious solidarities in Latin America" en Meyers, Albert y Hopkins, Diane Elizabeth (Eds.): Manipulating the saints: religious brotherhoods and social integration in postconquest Latin America, Wayasbah, Hamburgh, 1988, pág. 11.

40 Tardieu, Jean.Pierre: Les confréries de Noirs et de Mulâtres à Lima (fin XVI ${ }^{e}$-XVII ${ }^{e}$ siècle), Centre National Reserche Scientific, Bordeaux, 1989.

41 Celestino y Meyers: Las Cofradías en el Perú... Sobre la ayuda material, parte de las cuotas se destinaban a los miembros necesitados pero en ocasiones también a obras sociales en la comunidad. 
Señor de los Milagros, en la primera mitad del siglo XVII. Tras el fuerte terremoto de 1655 en Lima, algo muy común en Perú, se descubrió la imagen pintada de un Cristo de piel oscura en el único muro intacto de un conjunto de casas pobres destruidas, a las afueras de Lima. El hecho de que sólo quedara sin destruir la pared que soportaba esta pintura fue considerado un milagro y en ese momento un grupo de esclavos negros se dedicó a venerarlo como protección contra los terremotos. Poco después la devoción se amplió al resto de la población limeña, se pintó una copia de esta imagen que saldría en procesión una vez al año (hasta hoy), se construyó una iglesia (La Iglesia de las Nazarenas) que albergaría el muro original y se fundó una orden religiosa de mujeres que quedaría a su cuidado. ${ }^{42}$

Desde comienzos del siglo XVIII, aún en la época colonial, las instituciones políticas y religiosas de la Corona controlaron y respaldaron esta devoción al tiempo que se volvió una devoción popular en toda Lima. Encontramos cuadrillas de cargadores desde 1766, con el fin de celebrar los actos litúrgicos y la procesión en su honor, pero no se constituyen formalmente en asociación religiosa a pesar de que ese mismo año el Papa Clemente XII otorgara permiso para ello. ${ }^{43}$

Durante el siglo XIX, ya en la época de la Independencia, este tipo de asociaciones religiosas recobró cierta vitalidad asumiendo nuevas funciones civiles, en muchos casos como "agencias de crédito". Los distintos gobiernos de la República fueron confiscando sus propiedades, hasta entonces bajo control parroquial, pasando a la Beneficencia Pública, en medio de litigios entre ellas, la Iglesia y la Administración. Ello provocó el ser despojadas de sus bienes y, en definitiva, el fin de muchas de ellas pero también el surgimiento de otras con mayor autonomía financiera, pero con los mismos fines, organización interna y obligada supervisión eclesiástica. ${ }^{44}$

En el siglo XX, se observa una proliferación, a partir de los años cuarenta, de estas asociaciones religiosas (devotas también de otras imágenes) en el contexto de la emigración interna de las ciudades y pueblos del interior a la capital. Ellas representan para la población llegada a Lima una de

42 Vargas Ugarte, Rubén: Historia del Santo Cristo de los Milagros, Imprenta San Martí, Lima, 1966, págs. 30-31, 74 y 85; Banchero, Raul: Lima y el Mural de Pachacamilla. Historia del Señor de los Milagros de Nazarenas, del Monasterio y de la Hermandad; Aldo Raúl Arias Montesinos (editor), Lima, 1972, págs. 60-61; González La Rosa, M.: Vida de la V. Sierva de Dios Antonia Lucia del Espíritu Santo, fundadora del Monasterio de Nazarenas de Lima, Imprenta "El Nacional”, Lima, 1869.

43 Las propias monjas nazarenas solicitan el permiso al Papa. Vargas: Historia del Santo Cristo...; Banchero: Lima y el Mural...

44 Celestino y Meyers: Las Cofradías en el Perú..., capítulos IV al VII. 
las principales alternativas de organización comunitaria, cumpliendo funciones como las de preservar su identidad cultural, su realización personal o la búsqueda de prestigio, entre ellas las más populares son las hermandades del Señor de los Milagros. ${ }^{45}$ Éstas han sido fundadas en numerosos barrios de la capital (Barranco, La Victoria) pero también a diferentes Departamentos del Perú, extendiéndose el culto por el país y convirtiéndose en una devoción muy popular en todo el territorio nacional; ${ }^{46}$ más aún, su presencia se ha extendido a otros lugares donde los peruanos han emigrado, como por ejemplo Estados Unidos (California, Houston, Nueva York, Nueva Jersey, Miami), Canadá, Venezuela y Costa Rica. ${ }^{47}$

Hoy en día la devoción al Señor de los Milagros cuenta con una hermandad principal, formalmente constituida en 1955, que se denomina Hermandad de las Nazarenas de Lima (por su ubicación en la Iglesia del mismo nombre, donde se custodia la imagen original). En ella hay más de cuatrocientos mil hermanos, que se distribuyen en veinte cuadrillas de cargadores (doscientos cada una), dos grupos de cantoras y uno de sahumadoras (setecientas mujeres en total) que se ocupan de cantar y llevar el incienso durante la procesión. Es la más importante de Perú, tiene en su directiva nada menos que al Cardenal de $\operatorname{Lima}^{48}$ y se encarga de organizar la procesión más importante al Señor de los Milagros el día veintiocho de octubre, que cuenta con la presencia de las autoridades municipales y nacionales y se ha convertido en la más multitudinaria del mundo. ${ }^{49}$

Esta hermandad mantiene contactos con las hermandades creadas en el exterior ${ }^{50}$ y también se convertirá en el referente para las tres que se fun-

45 "En la Lima de 1965, hay registradas cerca de setenta cofradías, hermandades y otras asociaciones religiosas, entre las que se encuentra la del Señor de los Milagros de las Nazarenas, la más popular de todas ellas". Celestino y Meyers: Las Cofradías en el Perú.. pág. 226 y cuadro número 40 en Apéndices.

46 Ibídem, pág. 249. Además, el trabajo de campo entre los inmigrantes peruanos de Madrid también revela la existencia de estas hermandades en barrios limeños y pequeñas ciudades peruanas. Los entrevistados habían participado en ellas.

47 Altamirano, Teófilo: Éxodo. Peruanos en el exterior, Pontificia Universidad Católica del Perú, Lima, 1992.

48 Las cuadrillas se organizan en capataz, subcapataz, secretario, tesorero y prosecretario y, desde 1935, cada una tiene su “caja mortuorial”, una asociación civil paralela cuyas cuotas son aparte y sirven para cubrir los gastos de entierro de los hermanos. Banchero: Lima y el Mural... págs. 293-294. El Directorio Central contiene dieciocho cargos, entre ellos el de Director Espiritual, que lo ocupa el Cardenal de Lima. Datos obtenidos de la Secretaría de Relaciones Públicas de la Hermandad del Señor de los Milagros de las Nazarenas de Lima. (Entrevista: Lima, 12 de octubre de 1997).

49 Banchero: Lima y el Mural..., pág. 240, nota 5.

50 Secretaría de Relaciones Públicas de la Hermandad de las Nazarenas. (Entrevista: Lima, 12 de octubre, 1997). 
dan en Madrid en la década de los noventa, a ella pedirán sus estatutos, le comprarán una copia de la imagen original del Señor de los Milagros, imitarán sus ornamentos de la procesión y, algunas, incluso solicitarán su reconocimiento.

\section{El locus y los agentes de recreación de identidad ${ }^{51}$}

En 1994, a los pocos años del arribo de los inmigrantes peruanos en España, cuando ya había llegado la mitad del volumen en esa década, ${ }^{52} \mathrm{se}$ están conformando dos de las tres hermandades del Señor de los Milagros en Madrid: la agrupación de devotos ubicada en el centro de religiosas de María Inmaculada y la hermandad principal, en la parroquia de San Romualdo. Ambas celebran en el mes de octubre de ese año una misa en honor de la imagen, a la que acuden peruanos hasta llenar la iglesia, y un año después organizan su primera procesión. La hermandad de devotos del Señor de los Milagros de Majadahonda (población de la periferia de Madrid), en la parroquia de Santa María, celebrará la misa en 1995 y saldrá en procesión un año después.

Entre ellas, existen diferencias y similitudes: reúnen a diversos grupos de inmigrantes peruanos (según su momento de llegada, origen geográfico o composición social), mantienen relación con distintas asociaciones culturales y deportivas compatriotas, tienen un vínculo fuerte o débil según los casos con las instituciones consulares de su país, muestran un grado diferente de complejidad organizativa y de prestigio dentro de la comunidad peruana. Al mismo tiempo, encontramos en ellas la estructura y las actividades propias de una hermandad, un tejido asociativo, comunitario e institucional inmerso en el colectivo peruano, una particular interacción con las autoridades religiosas españolas y la elección de parroquias sensibilizadas con la presencia inmigrante en España.

51 La información presentada aquí sobre las hermandades peruanas en Madrid y sus dinámicas asociativas ha sido recogida a través de entrevistas y observación participante que realicé entre los miembros de la comunidad entre los años 1994 y 1999. Para una exposición más detallada sobre ellas y sobre el colectivo peruano (caracterización y análisis de las causas migratorias) ver Merino: Historia de los inmigrantes peruanos...)

52 Datos obtenidos en la explotación estadística de la base de datos del consulado peruano en Madrid, la fuente más completa sobre este colectivo. La fuerte inmigración peruana sucede a partir de 1990, y desde entonces hasta 1993 entra el 66.3\% del total de inscritos en el consulado hasta 1998 . 
Cada hermandad organiza su propio tejido asociativo, una red que abarca tres niveles: el comunitario, con los inmigrantes peruanos y sus vínculos familiares y de amistad, el asociativo, en su relación con asociaciones culturales, folclóricas y deportivas, y el institucional, con el Arzobispado, la parroquia, el consulado y la embajada peruanos y el ayuntamiento de su localidad. El conjunto de este espacio de relaciones dentro del colectivo se dinamiza y cobra sentido por la devoción al Señor de los Milagros; un elemento religioso y cultural que refuerza la cohesión entre los distintos participantes (individuos, entidades asociativas e instituciones) y genera un ámbito local de expresión cultural peruana.

En el nivel comunitario, hay que señalar la importancia de las redes familiares y de amistad como la vía idónea para la difusión de la idea de fundación de una hermandad, y la base de la cual surgirán sus futuros miembros; a su vez, el impulso de creación de este tipo de entidad reforzará los vínculos entre los peruanos a partir del sentimiento religioso común y la solidaridad que ello fomenta.

Las bases de estas hermandades es una población inmigrante peruana que, en muchos casos antes de venir a España había emigrado antes a la capital $^{53} \mathrm{o}$ tenía familiares que habían emigrado a otros países, lo que supone una población urbana con una capacidad ya desarrollada para adaptarse a nuevos contextos urbanos, apoyándose en extensas redes migratorias, familiares y de amistad. Una población inmigrante, más proclive al asociacionismo cultural y religioso que al político, que busca recuperar en España la posición social perdida en Lima por la situación crítica del país, económica y política. ${ }^{54}$

Respecto al vínculo asociativo, la relación de cada hermandad con las asociaciones culturales y deportivas peruanas surge en la búsqueda del apoyo social y económico de los compatriotas. La procesión del Señor de los Milagros requiere la compra de un conjunto de elementos: una copia de la imagen original, las andas sobre la que es paseada por las calles, lo que se completa, en algunos casos, con la imagen de la Virgen de las

53 Sobre la emigración interna en Perú, se puede consultar las siguientes obras. Degregori, Carlos, Blondet, Cecilia y Lynch, Nicolás: Conquistadores de un nuevo mundo, Instituto de Estudios Peruanos (IEP), Lima, 1986; Golte, Jurgen y Adams, Nora: Los caballos de Troya de los invasores, estrategias campesinas en la gran conquista de Lima, IEP, Lima, 1987; Contreras, Carlos y Cueto, Marcos: Historia del Perú Contemporáneo, Red para el desarrollo de las Ciencias Sociales en Perú, Lima, 2000.

54 Merino: Historia de los inmigrantes peruanos.... 
Nubes — como ocurre en la procesión principal de Lima- y otros ornamentos (flores, velas, etc.). La imagen sólo puede ser copiada, para ser legítima, por la Hermandad de las Nazarenas, en Lima, la que posee la pintura original; las hermandades de Madrid le comprarán una copia autorizada así como también le pedirán sus estatutos. La suma total de estos gastos oscila entre dos mil y cuatro mil dólares.

Semejante cifra no es posible reunir sin actividades de colecta entre los miembros de la comunidad peruana, por ello las hermandades organizan eventos culturales y deportivos, en los que participan los equipos de fútbol peruanos y las asociaciones culturales y folclóricas que se han ido creando unos años antes. ${ }^{55} \mathrm{Su}$ presencia en este tipo de actos asegura una mayor asistencia de peruanos (individuos, asociaciones o instituciones consulares), lo que significa no sólo mayor recaudación sino también el reconocimiento de su comunidad.

A través de campeonatos de fútbol y de actuaciones de música y danzas peruanas originarias de la costa, la sierra y la selva peruanas, estas entidades participan en las actividades de colecta, donde también encontramos comida típica peruana (papa a la huancaína, ají de gallina, etc.). Los eventos tienen lugar en diversos locales cedidos por la iglesia donde se ubican o por el ayuntamiento de diferentes zonas de Madrid, varias veces al año y la colecta se realiza a través de una aportación a la entrada, más el consumo posterior de bebidas. Numerosos peruanos acuden motivados por su finalidad religiosa, pero también por ver a sus equipos favoritos competir y a sus grupos folclóricos actuar; entre los asistentes resulta frecuente encontrar algún miembro del consulado o de la embajada peruanos.

55 Las asociaciones culturales son Casa Perú y Leganex; las primeras que se crearon, con miembros destacados de la comunidad peruana en España en los ochenta, como referente social de ese pequeño grupo, en estrecha relación con las autoridades consulares peruanas. Durante esa década sus actividades habían sido culturales y caritativas (eventos musicales para recaudar fondos en su ayuda a los menos favorecidos en Perú) pero, en los noventa, amplían su oferta para conectar con los recién llegados mediante la organización de un campeonato de fútbol, el patrocinio de un equipo o la conexión con las hermandades, sobre todo la de la iglesia de San Romualdo.

Las agrupaciones de música y baile se forman en España en la década de los noventa. Algunas de ellas son: Tradiciones Peruanas, Acuarela Criolla, Llaqta Perú, Inti Raimi y Todas las Sangres. Se trata de agrupaciones semi-profesionales, creadas y dirigidas por artistas profesionales en Perú conformadas por jóvenes inmigrantes peruanos motivados por la búsqueda de sus raíces culturales.

Los equipos de fútbol y sus ligas se organizan poco a poco entre los peruanos que llegan en esa época en sus lugares de encuentro. Pronto la actividad deportiva se convierte en un motivo importante de reunión semanal. Estos encuentros son espacios de sociabilidad donde también se comparte información, ayuda, así como música y comida peruana. Para más detalles, ver Merino: La Historia de los inmigrantes peruanos... 
Pero la relación entre hermandades, equipos de fútbol, asociaciones culturales y agrupaciones folclóricas va más allá de la mera colaboración en este tipo de actos. Hay equipos de fútbol que componen cuadrillas de cargadores y algunas hermandades patrocinan a su propio equipo entre los hermanos, que participa en los distintos campeonatos del colectivo; incluso, en una de las hermandades se ha creado el cargo de vocal deportivo dentro de la directiva. A su vez, los grupos de música y baile actúan cuando finaliza el recorrido de la procesión y colaboran en los preparativos de la misa celebrada antes de la salida procesional; en estas liturgias, algunos hermanos se visten con trajes tradicionales de la sierra y representan rituales andinos.

Como vemos, los elementos religiosos y culturales peruanos guardan una íntima relación; otra característica que los une es que ambos muestran y retoman el sincretismo cultural que caracteriza la Lima de estas últimas décadas. ${ }^{56}$ El Señor de los Milagros ya es una devoción popular en Perú igual que las canciones y bailes interpretadas por los grupos en sus actuaciones e igual que el fútbol. Se trata de expresiones culturales importadas de ese país con las que se sienten identificados un gran número de inmigrantes peruanos y que, en cierto modo, recuerdan su común origen nacional; por eso los peruanos acuden tanto a las actividades de colecta o la procesión de las hermandades como a la actuación de los grupos folclóricos en salas de espectáculos o a ver un partido de fútbol, de esto se compone su sociabilidad en España.

La importancia de las hermandades reside en conjugar e invocar esos elementos culturales en su interés por lograr que sus convocatorias religiosas o festivas tengan la mayor resonancia posible dentro del colectivo, lo que les permite ganar un prestigio que revierte en beneficio de la imagen de la comunidad peruana en Madrid. Por otro lado, el motivo religioso unifica y encauza esas pequeñas estructuras comunitarias que forman los seguidores de los grupos deportivos y culturales.

Si consideramos además el nivel institucional que abarcan las hermandades, todo lo expuesto hasta ahora cobra una nueva dimensión; ya que su relación con las autoridades eclesiásticas españolas abre un nuevo espa-

56 La inmigración del interior del Perú a su capital desde la década de los cuarenta fomenta ese sincretismo cultural en un país dividido geográfica y culturalmente en tres zonas: la costa, la sierra y la selva. Grompone, Romeo: El velero en el viento. Política y sociedad en Lima, IEP, Lima, 1991; Cotler, Julio: Perú 1964-1994. Economía, Sociedad y Política, IEP, Lima, 1995; Grompone, Romeo: Las nuevas reglas del juego: Transformaciones sociales, culturales y políticas en Lima, IEP, Lima, 1999. 
cio donde las hermandades negocian, como mediadoras interculturales, no sólo su propio reconocimiento sino también el de la religiosidad peruana y, por extensión, el de la cultura peruana.

Desde antes de existir estas entidades religiosas, los peruanos han acudido a parroquias españolas en busca de ayuda material y legal; esta relación se basa en la imagen que portan de la Iglesia Católica como defensora de los desvalidos en Perú y en la labor asistencial de algunas parroquias hacia los inmigrantes, de hecho, cada una donde se ubican las hermandades ya ha puesto en marcha o colaborado en programas de ayuda a los peruanos.$^{57}$ Precisamente, su sensibilidad hacia los recién llegados facilita la acogida de estas asociaciones religiosas las cuales, por otro lado, son entidades inmersas en la tradición católica y fueron instrumentos de control en el Nuevo Mundo.

Desde el principio, las autoridades eclesiásticas si bien acogen e impulsan su creación no lo harán sin poner algunas condiciones, tratando de evitar, en su opinión, uno de los peligros de una hermandad: la fragmentación de la comunidad católica universal, cuya verdadera fe se centra en la figura de Cristo y no en las múltiples imágenes objeto de devoción. ${ }^{58}$ Por ello, presionan para que los devotos del Señor de los Milagros acudan a otro tipo de actividades parroquiales como charlas o ejercicios espirituales, al tiempo que trata de obviar los elementos laicos y festivos de sus rituales. ${ }^{59}$

En su relación con las parroquias, las hermandades asumen varios papeles al mismo tiempo. En un primer momento aceptan esa imagen de "inmigrante económico", ya que muchos devotos se benefician de la ayuda parroquial, mientras fomentan su imagen de miembros de la comunidad

57 La Iglesia española asume su compromiso de ayuda desde el imaginario de los inmigrantes como personas que vienen de países pobres y pasan necesidad en España; de hecho, no es casualidad que la definición de "inmigrante económico" citada en un anterior apartado de este artículo apareciera en una publicación editada por Cáritas —entidad que colabora con las parroquias de Madrid—. Ver: Colectivo Ioé: "Los inmigrantes...". Se trata de la primera obra de carácter general que aborda el tema en profundidad y extensión. Se convertirá con posterioridad en referente de la producción bibliográfica sobre la inmigración en España.

58 Según los responsables de la iglesia, las directrices conciliares para las hermandades son la de fomentar una fe centrada en la figura de Cristo y evitar los desvíos de fe hacia los santos o las diferentes imágenes del Señor, argumentando que pueden llegar a convertirse en otra religión. Entrevista a una autoridad parroquial en la Iglesia de Santa María de Majadahonda, Madrid, 28 de febrero de 1998.

59 En España, la relación entre hermandades y parroquias sucede en esa misma tensión. Escalera, Javier: "Hermandades, religión oficial y poder en Andalucía" y Ariño, Antonio: "Las relaciones entre las asociaciones festeras y la institución eclesiástica", en Buxó, M. a Jesús et al (Coord.): La religiosidad popular, Anthropos-Fundación Machado, Barcelona, 1989, págs. 458-469 y 471-484. 
católica universal, con el cumplimiento de las exigencias religiosas que imponen los párrocos. Tras conseguir ser reconocidas oficialmente por la iglesia donde se ubican y el Arzobispado de Madrid y tras lograr el reconocimiento de la comunidad peruana (autoridad consular, asociaciones, individuos) las directivas de las hermandades van a cambiar poco a poco el juego, tratando de abrir un espacio para sus propias expresiones religiosas dentro de ese marco de Catolicismo Universal que defiende la Iglesia. Si bien un mayor apoyo de la comunidad peruana implica cierto grado de autonomía frente a las autoridades parroquiales, las hermandades ni pueden existir fuera del control eclesiástico ni quieren sustraerse de él.

A medida que las autoridades observan un incremento de las expresiones culturales peruanas y las interpretan, con alarma, como elementos que erosionan el carácter universal del catolicismo, tratarán de reducirlas; por su parte, las directivas de las hermandades tratarán de negociar de manera sutil su continuación apoyándose en el reconocimiento obtenido de su comunidad. Por ejemplo, en una de ellas los hermanos negocian la inclusión del vocal de deportes en su cuerpo directivo, mientras que aceptan mantener la imagen del Señor de los Milagros guardada en una sala fuera de la capilla central de la parroquia. Otra de ellas ha conseguido la ubicación de la imagen en un lugar destacado pero los hermanos principales despliegan una gran labor de colaboración en las actividades parroquiales. El seguimiento de éstas sólo es por parte de la directiva de las entidades, sin animar al resto de los devotos a hacer lo mismo.

Parece claro que los inmigrantes peruanos prefieren participar en las actividades religiosas y festivas de las hermandades que en las de la parroquia, ya que éstas les proveen de una imagen de pueblo rico en tradiciones. Por otro lado, en tanto que son devotos de una imagen católica, reconocida por la Iglesia del Perú, participan de una dimensión de la identidad española, la de ser católicos; de este modo forman parte de la sociedad española y de la suya de origen al mismo tiempo y, de paso, contrarrestan la imagen que les califica de forma peyorativa y excluyente como "inmigrantes económicos".

En el contexto migratorio español, estas manifestaciones de la cultura nacional peruana se limitan a la esfera local en tanto que son expresadas por grupos reducidos en torno a algunas parroquias españolas, pero para sus participantes peruanos representa el modo de renovar su vinculación con la comunidad nacional de origen y al mismo tiempo incorporarse de manera digna a la sociedad de acogida, sin suponer eso una contradicción interna, gracias a la dimensión supranacional, del Catolicismo. 
En este sentido, la devoción al Señor de los Milagros trasciende los límites territoriales que trata de reforzar la soberanía nacional española con la categoría de "inmigrante económico" y representa para los inmigrantes peruanos una vía de interacción y encuentro con la sociedad española.

\section{Conclusiones}

Los estados comunitarios, entre ellos España, adoptan las categorías de identidad acordadas en la Unión Europea, que organizan la presencia de los inmigrantes para, según su discurso, defender ese común territorio supranacional. La clasificación de "inmigrante económico", "asilado" e "ilegal" no sólo refuerza en España la frontera física sino también imaginaria entre la sociedad receptora (los de dentro) y los recién llegados (los de fuera) contribuyendo a la reificación del inmigrante como objeto sobre el que recaerán juicios de valor generalmente negativos.

En este contexto, nos encontramos que los inmigrantes peruanos crean hermandades en España como un elemento de reconstrucción comunitaria en un momento de desestructuración grupal y un medio de revitalización nacional ante la devaluación social que sufren por su posición de trabajadores de segunda categoría y su clasificación como "inmigrantes económicos". Este análisis no tendría más trascendencia desde el presente; pero ello significaría ignorar que España fue la metrópoli para los peruanos colonizados.

Si consideramos el fenómeno migratorio como parte de un mundo postcolonial podremos interpretar mejor hechos observables en la inmigración de latinoamericanos en España, de norte africanos en Francia o de asiáticos en Gran Bretaña; sujetos cuya percepción del país al que llegan y sus formas de asentamiento se ven marcadas por la experiencia histórica. Este estudio sobre las hermandades peruanas del Señor de los Milagros en España revela cómo las instituciones o los rasgos culturales impuestos durante el pasado colonial pueden servir como elementos de reencuentro y canal de comunicación.

No se presenta fácil la historia de los inmigrantes peruanos en España: el cierre de fronteras, el desarraigo, la inseguridad, la discriminación caracterizan el primer capítulo de su vida. Sin embargo, como inmigrantes de la globalización, son sujetos culturales ubicados en el centro de múltiples sistemas de referencia, lo que les permite diversificar los rostros de su identi- 
dad cultural e incrementar su capacidad para negociar y percibir las diferencias y similitudes con otras culturas, siempre limitados por unas estructuras de dominación y cierto margen de opciones a su alcance.

En este espacio globalizado y postcolonial, la creación de las hermandades a los inmigrantes peruanos y su dinamismo asociativo permite generar una imagen de sí mismos como católicos, una categoría universal que, por cumplir esta cualidad, puede contrarrestar ante la sociedad española esa otra imagen supranacional impuesta a su llegada, la de "inmigrantes económicos". No es una simple revitalización cultural de carácter nacional sino que busca además el reconocimiento de la sociedad receptora y con ello recuperar la dignidad de sus expresiones culturales y de lo que ellos son.

En el contexto de discriminación que encuentran en España, los inmigrantes peruanos negocian ese reconocimiento a partir de los elementos comunes con la nueva sociedad a través de mediadores religiosos, como lo eran los ladinos de la época colonial, de reconocida su autoridad por asumir la cultura colonizadora. No resulta extraño encontrar que las hermandades son acogidas en España, ya que en otra época fueron utilizadas como elemento de control sobre las comunidades conquistadas, ni tampoco el hecho de que tras siglos de colonización, lo católico sea un rasgo de identidad nacional peruana; así que resultan un medio idóneo para que los inmigrantes peruanos negocien localmente un espacio propio.

Resulta interesante observar cómo, en esa coyuntura, la religión católica, un sistema de referencia universal, sirve a los peruanos para articular relaciones comunitarias locales, no perder su vínculo con la sociedad de origen y desarrollar uno nuevo con la sociedad receptora, al tiempo que apostar por la dignificación de su imagen como comunidad.

Cuando los países europeos, como Francia, señalan la diversidad cultural como un problema, no la abordan en términos democráticos, no al menos en la práctica, donde sirve para ocultar otros problemas reales, económicos, políticos o sociales, como el desempleo o la escasa representatividad de los estados ante sus ciudadanos, y, de paso justificar la ideología racista y sus expresiones.

En el caso de la inmigración peruana a España, por ser este país de escasa experiencia ante la inmigración, aún no se hablaba, en la década de los noventa, de la diversidad cultural que traería consigo la inmigración. Por ello, fue posible que inmigrantes como los peruanos pudieran generar formas culturales híbridas, o recrear las que ya fueran híbridas, encontran- 
do elementos culturales comunes con la sociedad receptora y creando su propio espacio cultural y su dignidad desde la mezcla, no desde la construcción de una identidad pura o excluyente.

Sería interesante, a partir del presente estudio, comparar las dinámicas sociales y culturales de las hermandades del Señor de los Milagros creadas en otros países donde los peruanos han emigrado, como Estados Unidos o Venezuela. Ello permitiría, más allá de comprobar la hipótesis aquí planteada, comprender por qué la devoción al Señor de los Milagros es una de las expresiones culturales más importantes de las comunidades peruanas en el extranjero. Tal vez el contexto receptor no sea el mismo, ya que la combinación de la política migratoria del país receptor con el papel del Catolicismo en esos países no es la misma, ni esos países fueron metrópolis coloniales para Perú. Sin embargo, tal vez haya elementos comunes como la ambivalencia de lo local, lo nacional y lo supranacional en la devoción al Señor de los Milagros. Aún queda mucho que decir sobre el significado complejo de ser emigrante en la era de la globalización, con las contradicciones y el potencial implícito en cada nuevo encuentro entre culturas. 